\title{
A reorganização do circuito espacial da produção do vestuário no Brasil
}

La reorganisation du circuit spatial de la production de vêtements au Brésil

The reorganization of the spatial circuit of clothing production in Brazil

La re-organización del circuito espacial de la producción de vestuario em Brasil

\section{Silvana Cristina da Silva}

\section{(2) OpenEdition}

Journals

Edição electrónica

URL: http://journals.openedition.org/espacoeconomia/475

DOI: 10.4000/espacoeconomia.475

ISSN: 2317-7837

\section{Editora}

Núcleo de Pesquisa Espaço \& Economia

\section{Refêrencia eletrónica}

Silvana Cristina da Silva, «A reorganização do circuito espacial da produção do vestuário no Brasil », Espaço e Economia [Online], 3 | 2013, posto online no dia 19 dezembro 2013, consultado o 19 abril 2019. URL : http://journals.openedition.org/espacoeconomia/475; DOI : 10.4000/ espacoeconomia.475

Este documento foi criado de forma automática no dia 19 Abril 2019.

(C) NUPEE 


\title{
A reorganização do circuito espacial da produção do vestuário no Brasil
}

\author{
La reorganisation du circuit spatial de la production de vêtements au Brésil \\ The reorganization of the spatial circuit of clothing production in Brazil \\ La re-organización del circuito espacial de la producción de vestuario em Brasil
}

Silvana Cristina da Silva

\section{Introdução}

1 Pensar a geografia econômica hoje é pensar sobre a complexidade do mundo atual. Como alerta Martin (1996), houve muitas transformações nas relações entre os lugares e o mundo, e tais fenômenos demandam novas teorias geográficas para a análise dos sistemas produtivos. Martin (1996) ressalta a necessidade de considerarmos as particularidades dos lugares e as conexões com as escalas maiores. De fato, no período tecnocientífico e informacional (Santos, 2002) é impossível estudar o lugar pelo lugar.

2 No entanto, a Geografia precisou rever suas bases teóricas e metodológicas para explicar as mudanças contemporâneas. Para autores clássicos como George (1970), a Geografia Econômica tem por objeto de estudo as formas da produção, assim como a localização do consumo dos diferentes produtos no âmbito mundial. A distribuição dos homens pelo planeta, bem como os modos de produção e fabrico relacionados a esses grupos humanos são as chaves que explicam a vida econômica. Entretanto, George (1970) alerta sobre a primazia da indústria no entendimento dos mecanismos econômicos contemporâneos. Tomando como foco os territórios europeus, de fato a Geografia Econômica foi obrigada a debruçar-se sobre o processo de industrialização; por isso, muitas vezes a subdisciplina Geografia Econômica foi quase sinônimo de Geografia da Indústria.

3 A localização industrial e o desenvolvimento regional foram estudados classicamente com bases em três teorias: clássica, keynesiana e marxiana. Porém, entramos em uma nova fase do desenvolvimento econômico, sobretudo em virtude das mudanças e do uso das novas tecnologias da informação e comunicação (Martin, 1996). A Geografia da 
produção e do consumo transformou-se radicalmente após os anos 1970, havendo deslocamento da indústria dos territórios centrais para territórios periféricos como Brasil e Índia. Nesse novo período histórico e geográfico as atividades produtivas fundam-se em bases tecnocientíficas, na expansão do crédito, ou, melhor, na ascensão do capital financeiro e na publicidade que se associa à obsolescência programada dos produtos.

4 A Geografia Econômica trouxe várias teorias para explicar a maneira como a produção vem se organizando, entre as quais a escola da regulação ganha destaque. Martin (1996) sublinha o fato de essas teorias serem demasiadamente generalistas ou localistas ou mesmo abordarem as atividades econômicas a partir apenas da indústria. Tais teorias não se mostraram suficientemente fortes para a compreensão dos países periféricos, talvez nem mesmo para as economias avançadas na atualidade.

Por isso, é necessário enxergarmos o mundo a partir de teorias que considerem a globalização, vista do ponto de vista geográfico como a difusão do meio tecnocientífico e informacional (Santos, 2002); analisarmos os territórios a partir do seu uso e não do território em si, ou seja, o território usado (Santos e Silveira, 2001) - que diz respeito à maneira como as formas e ações combinam-se quantitativa- e qualitativamente e geram usos distintos, revelados nos lugares. Especialmente na análise da dialética entre o espaço e a economia, os circuitos espaciais de produção (Santos, 1986; Moraes, 1991) e a teoria dos dois circuitos da economia urbana (Santos, 2004) constituem um conjunto de possibilidades para a compreensão do complexo mundo das atividades produtivas que gera uma vida de relações (George, 1968) nos lugares além do econômico.

Dessa forma, apresentamos neste artigo o funcionamento empírico do ramo do vestuário com foco na cidade de São Paulo, conduzido pelos conceitos e teorias apresentadas anteriormente. Nosso objetivo é mostrar como se organiza o circuito espacial de produção do vestuário, ressaltando suas particularidades, e mostrar como, nos anos 1990, houve uma reorganização desse circuito e como o circuito espacial de produção, que é técnico e diz respeito à maneira como o "circuito das firmas" organiza a produção e dialoga com a economia urbana da cidade, formando o subsistema superior e o subsistema inferior.

\section{O circuito espacial de produção do vestuário}

7 O circuito espacial de produção constitui-se em circuitos de acumulação que se estruturam conforme as etapas produção, circulação, comércio e consumo (Santos, 1986; Moraes, 1991) até que a matéria-prima seja transformada em consumo - logo, em dinheiro e lucro para o agente que comanda o circuito da produção.

8 Tecnicamente, o circuito espacial de produção de vestuário se dá da seguinte maneira: na etapa de produção há a concepção da peça, elaboração do design, escolha da cor, modelagem e costura. Na sequência vem a distribuição, que se organiza de acordo com o ator que esteja no comando do circuito, isto é, o ator que comanda a acumulação (grandes marcas, redes varejistas, comerciantes de pequeno porte, feirantes etc.). Após a distribuição as peças são comercializadas, e novamente a forma de comercialização obedece ao tipo de ator que comanda o circuito. Se for de grandes marcas, há redes de lojas próprias ou autorizadas. No caso dos atacadistas, eles estão concentrados nas áreas de especialização do Brás e do Bom Retiro, na cidade de São Paulo, o que evidencia que estes dependem dessa aglomeração para sobressaírem no cenário nacional. Os pequenos comerciantes desses dois bairros de São Paulo e os expositores da Feira da Madrugada 
constituem outra situação dentro do circuito espacial do vestuário. Estes muitas vezes concentram todas as etapas da produção em um só agente, ou mesmo repassam a costura para pequenas oficinas, mas geram na cidade atividades e materialidades características do circuito inferior.

A produção de vestuário apresenta uma especificidade, que é a demanda de intensa mão de obra na etapa de costura, pois esse tipo de produção exige os movimentos refinados das mãos, ainda não substituíveis pelas máquinas. Com a forte industrialização da cidade, especialmente entre 1930 e 1970, São Paulo tornou-se concentradora das atividades do ramo têxtil, e com este surgiu a produção de vestuário. No entanto, nos anos 1980 houve uma forte crise econômica no País e desaceleração da indústria. Uma década depois, observa-se uma desconcentração industrial do ramo de vestuário para alguns lugares do território brasileiro. Entretanto, a categoria circuito espacial de produção nos ajuda a visualizar que em cada etapa da produção é possível gerar sinergias com os lugares e, ao mesmo tempo, as possibilidades de transporte e comunicação de longa distância também possibilitam a fragmentação cada vez maior do circuito espacial de produção.

Não podemos, contudo, confundir desconcentração de determinadas etapas da produção pelo território nacional (ou mesmo para outros territórios) com descentralização do capital. Basta observar onde estão as atividades dos circuitos espaciais de produção geradoras de atividades do circuito superior. Ainda que a costura e mesmo o consumidor possam estar dispersos no território, há centros de comando da produção que, em grande medida, revelam a centralização do capital. A divisão territorial do trabalho expressa a especialização produtiva dos lugares em tarefas que agregam mais valor dentro dos circuitos espaciais de produção. No entanto, o comando dos circuitos está localizado em poucos lugares.

\section{Reorganização da produção nos anos 1990}

11 Houve uma reorganização dos circuitos espaciais de produção em escala planetária. Muitas redes de comércio de vestuário e marcas mundialmente conhecidas dispersaram a produção por meio da subcontratação. Os países asiáticos, o Norte da África, o Leste Europeu, a América Central tornaram-se redutos da etapa de costura dentro dos circuitos planetários das grandes empresas do ramo de vestuário.

12 Além desses territórios, uma prática muito comum das empresas foi o uso de mãode obra imigrante no processo de produção nas grandes metrópoles: Nova Iorque, Paris e Los Angeles e mesmo São Paulo abrigam áreas de produção da indústria de vestuário. 0 imigrante, em virtude de sua situação de fragilidade, acaba transformando-se na mão de obra ideal para esse ramo. Na metrópole de São Paulo, os bolivianos compõem cerca de $70 \%$ da mão de obra de costura (Informação extraída do documentário "Nação oculta - os bolivianos em São Paulo", produzido por Diego Arraya, Mosaico Filmes, 2008).

13 Considerando a dinâmica regional brasileira, identificamos um forte processo de desconcentração da produção, na etapa de costura, no território brasileiro. As Tabelas $1 \mathrm{e}$ 2 mostram como o município de São Paulo perdeu pessoal ocupado e estabelecimentos no ramo de vestuário. São Paulo, que empregava $22,9 \%$ do pessoal ocupado no Brasil em 1994, passa a empregar, em 2009, 12,9\%. Observou-se queda também na participação do município com relação ao número de estabelecimentos, de $25 \%$ para $15 \%$. Entretanto, enfatizamos que a dispersão de uma etapa do circuito espacial não significa, 
necessariamente, perda de importância da atividade para a cidade de São Paulo, pois, como já apontamos, as grandes empresas comandam os circuitos de acumulação e atuam fortemente nas etapas de maior valor do circuito, como pesquisa, desenvolvimento, concepção, design, logística e comércio. Dessa forma, ainda que haja uma dispersão da produção, há também uma centralização das atividades mais sofisticadas na metrópole de São Paulo.

Tabela 1: Pessoal ocupado na produção de confecção e acessórios (1994 - 2009)

\begin{tabular}{|l|l|l|l|l|l|}
\hline & Município de SP & $\%$ & Estado deSP & $\%$ & Brasil \\
\hline 1994 & 88.319 & 22,9 & 150.768 & 39,2 & 384.952 \\
\hline 1995 & 79.382 & 22,2 & 136.937 & 38,2 & 358.286 \\
\hline 1996 & 68.925 & 19,7 & 124.105 & 35,5 & 349.530 \\
\hline 1997 & 58.461 & 17,0 & 110.542 & 32,2 & 343.097 \\
\hline 1998 & 52.850 & 15,3 & 104.098 & 30,0 & 346.499 \\
\hline 1999 & 56.176 & 14,9 & 109.253 & 29,0 & 376.803 \\
\hline 2000 & 60.854 & 14,8 & 118.615 & 28,8 & 411.272 \\
\hline 2001 & 59.300 & 14,1 & 118.608 & 28,2 & 421.138 \\
\hline 2002 & 60.912 & 13,7 & 121.662 & 27,4 & 444.365 \\
\hline 2003 & 59.910 & 13,4 & 123.125 & 27,5 & 448.524 \\
\hline 2004 & 65.006 & 13,1 & 137.719 & 27,8 & 495.727 \\
\hline 2005 & 68.232 & 13,1 & 145.400 & 27,8 & 522.717 \\
\hline 2006 & 73.938 & 13,4 & 154.911 & 28,0 & 552.430 \\
\hline 2007 & 78.144 & 13,2 & 161.903 & 27,4 & 591.226 \\
\hline 2008 & 81.252 & 13,1 & 165.714 & 26,8 & 618.595 \\
\hline 2009 & 81.454 & 166.620 & 26,3 & 632.350 \\
\hline
\end{tabular}

Fonte: RAIS-CAGED; elaboração da autora, 2011.

Tabela 2: Estabelecimentos de produção de confecção e acessórios (1994 - 2009)

\begin{tabular}{|l|l|l|l|l|l|}
\hline & Município de SP & $\%$ & Estado de SP & $\%$ & Brasil \\
\hline 1994 & 6.957 & 25,0 & 11.059 & 40,0 & 27.761 \\
\hline
\end{tabular}




\begin{tabular}{|c|c|c|c|c|c|}
\hline 1995 & 7.437 & 23,0 & 12.156 & 38,0 & 32.111 \\
\hline 1996 & 6.842 & 22,0 & 11.294 & 36,0 & 31.436 \\
\hline 1997 & 6.408 & 20,0 & 10.996 & 34,0 & 32.485 \\
\hline 1998 & 5.843 & 18,0 & 10.346 & 32,0 & 32.444 \\
\hline 1999 & 5.821 & 18,0 & 10.227 & 31,0 & 33.061 \\
\hline 2000 & 6.037 & 17,0 & 10.634 & 31,0 & 34.745 \\
\hline 2001 & 6.136 & 17,0 & 11.038 & 30,0 & 36.797 \\
\hline 2002 & 6.220 & 16,0 & 11.274 & 29,0 & 38.318 \\
\hline 2003 & 6.175 & 16,0 & 11.308 & 29,0 & 39.041 \\
\hline 2004 & 6.261 & 15,0 & 11.669 & 29,0 & 40.485 \\
\hline 2005 & 6.447 & 15,0 & 12.182 & 29,0 & 42.066 \\
\hline 2006 & 6.753 & 15,0 & 12.738 & 29,0 & 44.142 \\
\hline 2007 & 6.966 & 15,0 & 13.193 & 29,0 & 45.979 \\
\hline 2008 & 7.356 & 15,0 & 13.959 & 29,0 & 48.577 \\
\hline 2009 & 7.476 & 15,0 & 14.220 & 28,0 & 50.368 \\
\hline
\end{tabular}

Fonte: RAIS-CAGED; elaboração da autora, 2011.

14 A dispersão da produção, especialmente na subetapa de costura no circuito espacial de produção do vestuário, ocorreu em virtude dos altos preços da mão de obra nas áreas de produção mais antigas, como São Paulo, em função dos incentivos fiscais, tributários e territoriais oferecidos às empresas para se deslocarem para o Nordeste. $\mathrm{O}$ aumento da facilidade trazida pela maior densidade de transportes e comunicações também constitui fator fundamental para o deslocamento da produção para outras regiões do território brasileiro e mesmo do estado de São Paulo.

Lencioni (1991), estudando a reestruturação da indústria na metrópole de São Paulo a partir do ramo têxtil, alerta para o fato de que essas transformações têm como base o urbano, o industrial e o regional, afirmando (1991, p. 15) que "a reestruturação urbanoindustrial é condicionada pelos processos de concentração e centralização na reprodução do capital e sua manifestação se configura na desconcentração da metrópole". A autora acrescenta ainda que a dispersão da produção e mesmo o crescimento de algumas cidades do interior paulista fazem parte do processo de metropolização; não se trata de uma negação da metrópole, e sim de uma conformação da macrometrópole paulista, pois a dispersão ocorreu em um raio de até $150 \mathrm{~km}$ da capital. 
16 A outra face do processo de dispersão da produção são as formas de centralização do capital como associações de empresas de capital privado, absorções e fusões e a subcontratação (Lencioni, 1991).

17 A reorganização da produção nos países centrais, em que o emprego do sistema de subcontratação de oficinas tornou-se comum, teve rebatimentos concretos no território brasileiro, tanto com relação às empresas multinacionais que passaram a usar esse sistema, substituindo as grandes instalações industriais, como também em relação às empresas de médio porte que também passaram a se utilizar da subcontratação. Os comerciantes do Brás e do Bom Retiro, em grande parte, também terceirizam a etapa de produção.

18 Esse movimento revela que há um aprofundamento da divisão técnica do trabalho, juntamente com um aumento da especialização territorial do trabalho em determinadas etapas da produção. 0 comando do lucro concentra-se nos agentes do comércio; por isso, em período recente houve um significativo crescimento das empresas de varejo de vestuário no Brasil e há uma tendência à formação de conglomerados das grandes marcas.

19 A moda vem se tornando assunto para grandes investidores, e, segundo reportagem da revista Época (18/2/2008), o Brasil passa por processo semelhante ao ocorrido na Europa nos anos 1980, em que as grandes marcas da alta-costura, como Gucci, Armani e Louis Vuitton, passaram a ser compradas e controladas por grandes corporações, em geral conglomerados financeiros. Essas grifes foram compradas por corporações como a francesa LVMH, cujo valor de mercado está próximo de US\$ 54 bilhões. O grupo é dono de mais de 50 marcas de luxo, entre elas Dior e Fendi. Seu principal rival no mundo é o grupo PPR, também francês, que cuida de marcas como Gucci e Balenciaga. No Brasil, foi criada em 2008 a holding Inbrands, com 50\% do UBS Pactual (banco suíço-brasileiro), 42,5\% de Alvarenga (sócio-fundador da Ellus) e 7,5\% de Breia (sócio da Ellus). Para criar a holding, o banco entrou com uma quantia estimada em R $\$ 100$ milhões, enquanto Alvarenga e o sócio aportaram o patrimônio da empresa, que fatura $\mathrm{R} \$ 200$ milhões por ano (revista Época, 2008). Esse processo reitera as mudanças de estratégias dos investimentos dos grupos industriais apontadas por Arroyo (2006), ou seja, as empresas industriais vêm colocando seus ativos em aplicações financeiras, corroborando o movimento de "financeirização da riqueza", no qual o maior problema é o caráter rentista desse movimento. Mesmo em uma atividade industrial tradicional como a do vestuário tais processos se implantaram.

20 Dessa forma, os atores que comandam os circuitos produtivos - aqueles que se beneficiam da valorização do capital, ao longo das etapas de produção - correspondem ao grande capital, e localizam-se nas grandes metrópoles mundiais. Mesmo que dispersem a produção, a inteligência das empresas necessita de lugares nos quais a racionalidade científica, a densidade comunicacional e de circulação e os serviços quaternários estejam presentes (consultorias jurídicas, de informática, logística, financeiras, agências de publicidade etc.); por isso as sedes de poder encontram-se em pouquíssimo lugares.

Destacamos, entretanto, que há atores que compõem outras situações do circuito espacial de produção, como os pequenos e médios comerciantes do Brás e do Bom Retiro, que dependem do território para sua sobrevivência e também subcontratam a etapa de costura, mas restringem-se aos limites das áreas de especialização da metrópole, podendo até ir além dela, mas não muito longe. $O$ comércio para esses agentes depende da dinâmica das áreas de especialização. Os bairros paulistanos do Brás e Bom Retiro 
tornaram-se referência nacional no comércio atacadista de confecções e atraem fluxos de pessoas de todo o Brasil.

\section{Os circuitos produtivos e os dois circuitos da economia urbana na metrópole de São Paulo}

Santos (2004) propõe uma alternativa teórica para explicar a urbanização dos países periféricos, pois para esse autor a urbanização dos países pobres não pode ser vista como a repetição da urbanização europeia no período pré-industrial. Além disso, os territórios periféricos são integrados à economia mundial para exercer um papel na divisão internacional do trabalho, papel esse determinado por demandas extravertidas. Logo, foram criados os mecanismos de dependência, dos quais o mais conhecido e explícito foi o Pacto Colonial. No entanto, na era da globalização os pactos se renovam e os mecanismos de dependência são outros, como, por exemplo, a dependência tecnológica e dos capitais financeiros.

Santos $(1976,1977,2004)$ propõe que interpretemos as cidades como um sistema econômico, subdividido em dois subsistemas, os dois circuitos da economia, o que autoriza que se trate a cidade como uma totalidade. Por isso é impossível falar do circuito superior sem falar do circuito inferior; ainda que o circuito inferior seja em grande medida dominado pelo superior, ambos estão estruturalmente conectados por uma relação dialética de subordinação, complementaridade e concorrência. A economia urbana é uma totalidade e tanto o circuito superior como o inferior estão subordinados às leis gerais de funcionamento do capitalista. Dessa forma, os subsistemas urbanos nascem a partir da

[...] existência de uma massa de pessoas com salários muito baixos ou vivendo de atividades ocasionais, ao lado de uma minoria com rendas muito elevadas, [que] cria na sociedade urbana uma divisão entre aqueles que podem ter acesso de maneira permanente aos bens e serviços oferecidos e aqueles que, tendo as mesmas necessidades, não têm condições de satisfazê-las. Isso cria ao mesmo tempo diferenças quantitativas e qualitativas no consumo. Essas diferenças são causa e efeito da existência, ou seja, da criação ou manutenção, nessas cidades, de dois circuitos de produção, distribuição e consumo de bens e serviços" (SANTOS, 2004, p. 37).

24 Essa dinâmica do sistema urbano surge das modernizações tecnológicas que, por sua vez, são comandas pelo Estado e pelas grandes empresas. Colocando em diálogo a categoria circuito espacial de produção com a teoria dos dois circuitos da economia urbana, unimos as propriedades técnicas da produção, "circuito das firmas", com economia urbana. Esta constitui o modo como se organizam as materialidades, divisão territorial do trabalho, a partir do conjunto de circuitos produtivos que se implantam nas cidades -- ou seja, formas urbanas surgem a partir da repartição da produção, que é comandada por diferentes atores e com distintos poderes de estruturação do espaço. Por isso encontramos a cidade luminosa e a cidade opaca coexistindo não em dualidade, mas sim em oposição conectada estruturalmente.

As grandes redes varejistas de vestuário que atuam no território nacional compõem o circuito superior da economia urbana. Tais empresas vêm expandindo sua atuação com elevados investimentos em pesquisa e desenvolvimento, design, marketing, logística de distribuição, comércio e apelo à expansão do consumo pautado no binômio formado por 
publicidade e ampliação do crédito. As atividades mais sofisticadas e o comércio dessas empresas localizam-se em São Paulo.

Entre as grandes redes varejistas de atuação nacional, como Riachuelo, Marisa, Pernambucanas e Renner, apenas a última possui escritório fora de São Paulo. Das redes internacionais, Zara e C\&A possuem escritórios na cidade de São Paulo. Tanto as grandes marcas quanto os varejistas subcontratam as oficinas de costura para produção das peças. Assim, encontramos os nexos entre os dois subsistemas urbanos por meio da materialização dos circuitos espaciais.

Os lojistas do Brás e do Bom Retiro representam outra situação da produção que gerou formas urbanas na cidade de São Paulo capazes de condicionar a ação desses agentes promotores dos circuitos produtivos.

28 Allan Pred (1979), analisando as cidades nas economias avançadas, define que o sistema de cidades é um conjunto nacional ou regional de cidades que funcionam de modo interdependente, ou seja, qualquer mudança significativa nas atividades econômicas, na estrutura ocupacional ou na renda da população de uma cidade pode desencadear mudanças nas outras cidades que compõem o sistema.

29 Nos sistemas de cidades, as metrópoles cumprem papel insigne, pois, segundo Pred (1979), as relações entre insumo e produto ou relações de controle de emprego e tomada de decisões dentro das empresas multinacionais e órgãos de governo são elementos importantes para o conjunto das cidades que obedecem à tendenciosidade espacial da informação, uma vez que a localização das atividades econômicas obedece a decisões explícitas (localização de órgãos de governo e disponibilidade de informações especializadas são fundamentais para a difusão de inovações por outras empresas) e implícitas (quando uma empresa ou órgão de governo decide adquirir bens e serviços, rotineiros ou não) que corroboram para a tendenciosidade espacial. Essa tendenciosidade espacial condiciona a escolha dos lugares para implantação de unidades empresariais como agências de publicidade, bancos, sedes administrativas, etc., que exigem que parte do tempo seja gasta na troca de informações e na relação direta com os clientes.

As cidades dos países periféricos, como já ressaltamos, apresentam outro padrão de organização, mas algumas características da urbanização nas economias avançadas também são observadas nos territórios periféricos. É o caso da concentração de atividades industriais e de produção de informação.

31 Como mostra Adriana B. da Silva (2001), a cidade de São Paulo abriga densamente as atividades produtoras de informação. Essa produção de informação é substrato para o funcionamento do complexo emaranhado de circuitos produtivos que convergem na metrópole. Escritórios de advocacia, consultorias financeiras e de informática, grandes agências de publicidade, sedes de grandes bancos, sedes de instituições públicas importantes são expressões do poder de comando dos fluxos materiais e imateriais da cidade de São Paulo. Além disso, a construção da cidade para a fluidez por meio do sistema rodoviário, torre de controle do movimento de helicópteros, a presença de aeroportos, além dos equipamentos culturais e de lazer - como museus, shoppings, teatros, bibliotecas, grandes exposições internacionais -, permitem a presença de um tipo de população ligada ao comando dos circuitos produtivos que fazem da metrópole um lugar luminoso, que muitas vezes ganha a denominação cidade global.

A informação hegemônica, imposta pelas grandes empresas da "indústria da moda", coexiste com a informação usada como resistência nos microcircuitos das confecções, que 
abrigam um grande volume de mão de obra. A cidade de São Paulo torna-se um centro informacional, dada a sua capacidade de produção, organização e distribuição da informação hegemônica, e ao mesmo tempo torna-se centro do uso da informação não hegemônica, assim como amplia seu papel produtivo pela via do circuito inferior.

\section{Considerações finais}

O diferencial que se observa no uso da categoria circuito espacial de produção é que, em grande medida, resolve-se o problema da complexidade da divisão das atividades econômicas em setores e assim identificamos o circuito. Desse modo, a Geografia Econômica não precisa ser uma Geografia da Indústria ou dos Serviços ou do Consumo, pois as etapas do circuito espacial de produção estão conectadas e criam materialidades, ou seja, criam uma divisão territorial do trabalho, que por sua vez vai condicionar a própria existência dos circuitos.

O diálogo entre os circuitos espaciais de produção e os dois circuitos da economia urbana apresenta-se produtivo na medida em que o circuito técnico, das firmas, pode ser revelado pelas atividades urbanas, estas pertencentes ao circuito superior, superior marginal ou inferior, que funcionam dialeticamente em forma de dominação, subordinação, complementaridade e concorrência, formando o subsistema urbano.

$\mathrm{Na}$ análise do ramo de atividade do vestuário verificamos que cada ator gera materialidades específicas nas cidades e na economia política da urbanização por meio da organização do seu circuito produtivo. Quanto mais poderoso é esse ator, maior a sua capacidade de ampliação dos seus círculos de cooperação, chegando à escala planetária. Já os agentes que têm menor poder de criar materialidades e fluxos dependem mais da contiguidade para existirem. Esse é o caso dos atacadistas do Brás e do Bom Retiro. Os expositores da Feira da Madrugada e o pequeno comércio de confecções nesses dois bairros formam um circuito espacial de produção que gera muitas atividades caracterizadas como de circuito inferior. Usufruem de partes da cidade que foram abandonadas pelos agentes hegemônicos e, ao mesmo tempo, deram dinamismo a essas áreas e vêm mobilizando fluxos nacionais relacionados ao comércio de confecção, ainda que sejam dependentes do ambiente construído da metrópole deteriorada para a execução das etapas do circuito.

Apesar da reorganização do circuito do vestuário nos anos 1990, a visão do processo possibilitada pela análise do circuito espacial de produção mostra que o capital centralizase, sobretudo ao comandar o circuito em pontos estratégicos do território. Além disso, a prática sistemática de subcontratação é outra forma de encontrarmos a dialética entre as atividades modernas e não modernas presentes nas cidades brasileiras, sobretudo nas metrópoles. 


\section{BIBLIOGRAFIA}

ARROYO, M. A vulnerabilidade dos territórios nacionais latino-americanos: o papel das finanças. In: LEMOS, A. I., SILVEIRA, M. L., ARROYO, M. (org.). Questões territoriais na América Latina. Buenos Aires: Clacso, 2006.

GEORGE, P. Geografia econômica. Rio de Janeiro: Fundo de Cultura, 1970 [1958]. . A ação do homem. São Paulo: Difusão Europeia do Livro, 1968.

LENCIONI, S. Reestruturação urbano-industrial: centralização do capital e desconcentração da metrópole de São Paulo - a indústria têxtil. Tese de doutorado. FFLCH-USP. São Paulo, 1991. 286p.

MARTIN, R. Teoria econômica e geografia humana. In: GREGORY, D.; MARTIN, R.; SMITH, G. (orgs.). Geografia humana: sociedade, espaço e ciência social. Rio de Janeiro: Jorge Zahar Editores, 1996 [1994].

MORAES, A. C. R.. Los circuitos espaciales de la producción y los círculos de cooperación en el espacio. In: Aportes para el estudio del espacio socio-economico III. Yanes, L. e Liberali, A. M. (orgs.). Buenos Aires, El Coloquio, 1991. p.153-77.

PRED, A. Sistema de cidades em economias adiantadas. Crescimento passado, processos presentes e opções de desenvolvimento futuro. Rio de Janeiro: Zahar Editores, 1979 [1977].

REVISTA ÉPOCA. Eles estão na moda. 18 de fevereiro de 2008. Disponível em < http:// epocanegocios.globo.com/Revista/Epocanegocios/0,EDG81539-8385-12,00-ELES+ESTAO+NA +MODA.html> Acesso em 26/3/2011.

SANTOS, M. Le circuit inférieur: le soi-disant secteur informel. Les Temps Modernes, novembre, XXX année, 1976. p. 741-755.

. Desenvolvimento econômico e urbanização em países subdesenvolvidos: os dois subsistemas de fluxo da economia urbana e suas implicações espaciais. Boletim Paulista de Geografia , 53, fevereiro de 1977. p. 35-60.

. O espaço dividido: os dois circuitos da economia urbana dos países subdesenvolvidos. São Paulo: Edusp, 2004 [1979].

. Circuitos espaciais da produção: um comentário. In: SOUZA, M. A.; SANTOS, M (Org.). A construção do espaço. São Paulo: Nobel, 1986. p. 121-34.

. A natureza do espaço: técnica e tempo, razão e emoção. São Paulo: Edusp, 2002 [1996].

SANTOS, M. \& SILVEIRA, M. L. O Brasil território e sociedade no início do século XXI. Rio de Janeiro: Record, 2001.

SILVA, A. M. B.. A contemporaneidade de São Paulo. Produção de informações e reorganização do território brasileiro. Tese de Doutorado. Departamento de Geografia, FFLCH- USP, 2001. 282f.

\section{RESUMOS}

O presente texto visa analisar o processo de reorganização do circuito espacial de produção do vestuário no Brasil atual. Grandes mudanças ocorreram no ramo de confecção do território 
brasileiro (sobretudo na década de noventa), com destaque para a desconcentração da etapa da produção e a centralização do capital das empresas que comandam os circuitos de acumulação. A introdução sistemática da subcontratação no processo produtivo do vestuário vem aprofundando a divisão técnica e territorial do trabalho, cabendo às grandes empresas (compostas por grandes varejistas e marcas) executarem as etapas de pesquisa, concepção, design, logística e marketing, enquanto as pequenas oficinas realizam a fase da costura. Grosso modo, as empresas formam parte do circuito superior da economia e as oficinas compõem o circuito inferior. Nossa investigação trabalha com o conceito de território usado, pois os lugares revelam como as materialidades condicionam as ações e como as ações criam-recriam as materialidades.

Cet article vise à comprendre le procès de réorganisation du circuit spatial de la production de vêtements dans le Brésil actuel. Des grandes transformations ont eu lieu dans le secteur textile dans le territoire brésilien (surtout dans les années 1990), notamment le décentrement de l'étape de la production et la centralisation du capital des entreprises qui commandent les circuits de l'accumulation. L'introduction systématique de la sous-traitance dans le procès de la production des vêtements est en train d'approfondir la division technique du travail : c'est aux grandes entreprises (notamment les grandes marques et concessionnaires) d'exécuter les étapes de la recherche, conception, dessin, logistique et marketing, tandis que les petits ateliers réalisent la phase de la couture. Grosso modo, les entreprises forment le circuit supérieur de l'économie, et les ateliers le circuit inférieur. Notre recherche utilise le concept de territoire utilisé, car les lieux révèlent comme les matérialités conditionnent les actions et les actions créent-ré-créent les matérialités.

This papers aims to understand the reorganization process of the production of clothing in present Brazil. Great transformations took place in the confection's sector in the Brazilian territory (namely in the 1990's), in particular the decentralization of the production step and the centralization of the capital by the enterprises which lead the accumulation circuits. The systematic introduction of subcontracting in the clothes' production process is augmenting the technical division of work: big enterprises (namely big marks and concessionaries) execute the steps of research, conception, design, logistic and marketing, whereas little workshops realize the sewing step. Approximately, enterprises constitute the upper economy's circuit, and workshops the lower one. Our research uses the concept of used territory, because places reveal that materiality conditions action, and action re-create materiality.

El presente texto tiene el objetivo de analizar el proceso de re-organización del circuito espacial de la producción de vestuario en el Brasil actual. Grandes cambios ocurrieron en el ramo de la confección en el territorio brasileño (sobre todo en la década de noventa), con énfasis en la desconcentración de la etapa de la producción y la centralización del capital de las empresas que encabezan los circuitos de acumulación. La introducción sistemática de la sub-contratación en el proceso productivo del vestuario viene profundizando la división técnica y territorial del trabajo, dejando para las grandes empresas (compuestas por grandes almacenes de cadena y marcas) la ejecución de las etapas de investigación, concepción, diseño, logística y marketing, mientras que los pequeños talleres realizan la etapa de costura. En términos generales, las empresas forman parte del circuito superior de la economía y los talleres componen el circuito inferior. Nuestra investigación trabaja con el concepto de territorio usado, pues los lugares revelan como las materialidades condicionan las acciones y como las acciones crean y re-crean las materialidades. 
ÍNDICE

Mots-clés: territoire utilisé, circuits spatiaux de production, circuit inférieur, circuit supérieur, vêtements

Palavras-chave: território usado, circuitos espaciais de produção, circuito inferior, circuito superior, vestuário

Keywords: used territory, spatial circuits of production, lower economic circuit, upper economic circuit, clothing

Palabras claves: territorio usado, circuitos espaciales de producción, circuito infeiror, circuito superior, vestuario

\section{AUTOR}

\section{SILVANA CRISTINA DA SILVA}

Doutora em Geografia pela Unicamp. Professora Adjunta, Universidade Federal Fluminense,

Departamento de Geografia. Grupo de Pesquisa Território e Cidades. Email: silvanasilva@id.uff.br 